\title{
Exposure to household secondhand smoke among adolescents in Kuwait: Results from two school-based cross-sectional studies
}

\author{
Ali H. Ziyab' , Mohammad Almari², Abdullah Al-Taiar ${ }^{3}$
}

\begin{abstract}
INTRODUCTION Detrimental effects of secondhand smoke (SHS) exposure are well established; however, data on SHS exposure among adolescents in Kuwait are lacking. Hence, this study sought to estimate the prevalence of household SHS exposure among two samples of adolescents in Kuwait and assess its variation by socioeconomic status and parental education level.

METHODS Data from two large school-based cross-sectional studies were analyzed. Adolescents attending public middle ( $\mathrm{n}=3864$; aged $11-14$ years $)$ and high ( $\mathrm{n}=1959$; aged 14-19 years) schools throughout Kuwait were enrolled in 20162017, and parental self-reported household SHS exposure was ascertained. Associations were assessed using Poisson regression with robust variance estimation, and adjusted prevalence ratios (APRs) and 95\% confidence intervals (CIs) were estimated.

RESULTS Overall, $45.8 \%$ (1755/3836; 95\% CI: 44.2-47.3\%) of the enrolled middle school students and 51.6\% (998/1936; 95\% CI: 49.3-53.8\%) of the enrolled high school students were exposed to household SHS. Among middle and high school students, the prevalence of household SHS exposure increased as maternal/ paternal education level and family income decreased. Among middle school students, paternal educational attainment of middle school or less compared to bachelor's degree or higher was associated with 1.60 times (95\% CI: 1.44-1.79) higher household SHS exposure. Similarly, in the sample of middle school students, the prevalence of household SHS exposure significantly increased from $35.8 \%$ among children from families reporting the highest household income to $50.5 \%$ among children from families with the lowest reported household income ( $\mathrm{p}$-trend<0.001).

CONCLUSIONS Household SHS exposure is substantially high among adolescents in Kuwait. Enrolled adolescents from families with low socioeconomic status or with low parental education level have the highest household SHS exposure. These findings highlight the need for national comprehensive tobacco control policies and increasing parental awareness of the impact of SHS exposure on children.
\end{abstract}

\section{INTRODUCTION}

Tobacco smoking, a preventable cause of morbidity and mortality, remains a major global public health challenge. No less, exposure to secondhand smoke (SHS), also referred to as passive or environmental

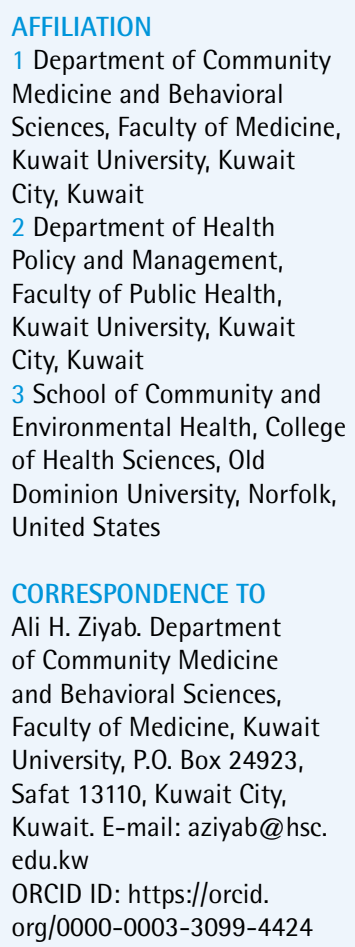

1 Department of Community Medicine and Behavioral Sciences, Faculty of Medicine, Kuwait University, Kuwait City, Kuwait

2 Department of Health Policy and Management, Faculty of Public Health, Kuwait University, Kuwait City, Kuwait

3 School of Community and Environmental Health, College of Health Sciences, Old Dominion University, Norfolk, United States

CORRESPONDENCE TO Ali H. Ziyab. Department of Community Medicine and Behavioral Sciences, Faculty of Medicine, Kuwait University, P.0. Box 24923, Safat 13110, Kuwait City, Kuwait. E-mail: aziyab@hsc. edu.kw

ORCID ID: https://orcid. org/0000-0003-3099-4424

\section{KEYWORDS}

secondhand smoke, adolescents, Kuwait, epidemiology

Received: 21 November 2019 Revised: 6 February 2020 Accepted: 16 March 2020 
to mortality in adults who never smoke ${ }^{2}$. Children exposed to SHS have a higher risk of sudden infant death syndrome, acute respiratory infection, severe asthma, and slow lung growth ${ }^{1}$. Moreover, accumulated evidence suggests that SHS exposure is associated with cardiovascular consequences in children $^{3}$. Similarly, adults exposed to SHS have a higher risk of lung cancer and other cancers in addition to adverse effects on the cardiovascular system including arterial stiffness, atherosclerosis, and endothelial dysfunction ${ }^{1,4}$.

Global estimates from 2004 showed that $40 \%$ of children, $35 \%$ of adult female non-smokers, and $33 \%$ of adult male non-smokers were exposed to $\mathrm{SHS}^{5}$. Among adolescents living in low- and middle-income countries, the overall prevalence of SHS exposure was estimated to be $55.9 \%$, with the lowest estimate of $16.4 \%$ reported in Tajikistan and the highest estimate of $85.4 \%$ reported in Indonesia ${ }^{6}$. Decreasing trends in SHS exposure among children have been reported in several countries, including Germany ${ }^{7}$, Australia ${ }^{8}$, Denmark $^{9}$, the United Kingdom ${ }^{10-12}$, and the United States ${ }^{13}$. Nevertheless, socioeconomic disparities in the prevalence of SHS exposure among children exist. For instance, exposure to SHS is highest among children of parents with lower education attainment ${ }^{14-16}$. Similarly, family income has been shown to be inversely associated with childhood exposure to $\mathrm{SHS}^{16-18}$. Such socioeconomic disparities seem to persist over time ${ }^{7,8,10}$.

Analysis of the burden of disease from SHS exposure showed that $61 \%$ of total SHS-attributable disability-adjusted life-years were in children ${ }^{5}$. Hence, developing, implementing and enforcing comprehensive smoke-free laws in all indoor workplaces and public places, as well as smoke-free home and vehicle rules, will probably reduce the burden attributed to SHS exposure among nonsmoker adults and children/adolescents. Although epidemiologic characterization of SHS exposure in most developed countries is thorough, some countries still lack such empirical knowledge. Hence, to inform public health officials and policymakers, this study aimed to report, for the first time, the magnitude of household SHS exposure among samples of middle and high school students in Kuwait and to describe disparities in household SHS exposure according to parental education and socioeconomic status.

\section{METHODS}

\section{Study setting, design and population}

Data from two large school-based cross-sectional studies were analyzed and reported in this investigation. The first study was a cross-sectional study that enrolled schoolchildren $(n=3864)$ attending public middle schools across all governorates of Kuwait, which included children aged between 11 and 14 years. The schoolchildren were enrolled in the study during the 2016-2017 school year (September 2016 to May 2017) and the first semester of the 2017-2018 school year (September to December 2017). A stratified two-stage cluster sampling method was used to select a representative study sample of schoolchildren from a random sample of middle schools across Kuwait. The sampling methodology is described in detail elsewhere ${ }^{19}$. In the current report, we analyzed data from 3836 participants with information on household SHS exposure (i.e. excluding 28 participants with missing information). Parents provided written informed consent to enrol their children in the study and completed study questionnaires. Ethical approval was obtained from the Standing Committee for Coordination of Health and Medical Research, Ministry of Health, Kuwait (No. 2016/451).

The second study was a cross-sectional study that enrolled high school students $(n=1959)$ attending public schools across Kuwait, which typically include students aged between 14 and 19 years. Recruitment of study participants occurred during the first semester of the 2017-2018 school year (September to December 2017). To ensure a representative study sample, a cluster random sampling method was used in selecting schools and students, as detailed by Almari et al. ${ }^{20}$. In this analysis, data from 1936 participants with information on household SHS exposure were used (i.e. excluding 23 participants with missing information). Upon obtaining parental written informed consent, selfadministered questionnaires were completed by parents and students. This study was approved by the Health Sciences Center Ethical Committee at Kuwait University (No. VDR/EC/3067). It is worth noting that school enrollment is very high in Kuwait for both females and males and that data from both studies can be extrapolated to all adolescents in the country. 


\section{Ascertainment of SHS exposure and covariates}

In both studies, exposure to household SHS was ascertained by an affirmative response by parents to the question: 'Does anyone smoke cigarettes or waterpipe inside the house?'. This approach allowed us to estimate the point prevalence of household SHS exposure. Age was categorized as: $\leq 11,12,13$, and $\geq 14$ years in the middle school students, with age $\leq 11$ years being the reference group. Moreover, among high school students, age was reported as: $\leq 15,16$, and $\geq 17$ years, with age $\leq 15$ years being the reference group. Information on maternal and paternal level of education was obtained in both studies with the following options: middle school or less, high school, diploma (a two-year associate degree post high school), and bachelor's degree or higher as the reference group. Total monthly family income in Kuwaiti Dinar (1 KWD about 3.21 US\$) was reported by parents in both studies as: $<1000,1000-1500$, 1501-2000, 2001-2500, 2501-3000, and $>3000$ as the reference group. Information on cigarette selfsmoking was sought from the enrolled high school students by asking the following question: 'Have you smoked at least one combustible cigarette in the past 30 days?'. This approached allowed us to determine current cigarette smoking status.

\section{Statistical analysis}

All statistical analyses were conducted using SAS 9.4 (SAS Institute, Cary, North Carolina, USA). The statistical significance level was set to $a=0.05$. Prevalence of household SHS exposure was determined in the total study samples and across categories of different variables. Prevalence ratios (PRs) and 95\% confidence intervals (CIs) that assessed associations between different covariates and SHS exposure were estimated by applying a modified Poisson regression with robust variance estimation using the GENMOD procedure in SAS 9. $4^{21}$.

\section{RESULTS}

Table 1 shows characteristics of the two analyzed study samples. In total, 3864 middle school students were enrolled, of which 3836 (2154 girls and 1682 boys) participants were analyzed in this report (i.e. excluding 28 participants with missing information on household SHS exposure; Table 1). The median (5th, 95th percentile) age of the middle school study participants was $12.0(11.0,14.0)$ years. Majority of the enrolled middle school children's mothers $(42.7 \%, 1626 / 3806)$ and fathers $(35.7 \%, 1353 / 3786)$

Table 1. Characteristics of the two analyzed study samples of Kuwait, 2016-2017

\begin{tabular}{|c|c|c|}
\hline Characteristics & $\begin{array}{l}\text { Viddlle } \\
\text { School } \\
\text { students } \\
\text { (n-3836) } \\
\%(\mathrm{n})\end{array}$ & $\begin{array}{l}\text { Iligh School } \\
\text { students } \\
(\text { n }-1936) \\
\%(\text { m) }\end{array}$ \\
\hline \multicolumn{3}{|l|}{ Adolescent gender } \\
\hline Female & $56.2(2154)$ & $54.2(1049)$ \\
\hline Male & $43.8(1682)$ & $45.8(887)$ \\
\hline Missing, (n) & $(0)$ & (0) \\
\hline \multicolumn{3}{|l|}{ Adolescent age group (years) } \\
\hline$\leq 11^{\mathrm{a}}$ & 27.6 (1059) & - \\
\hline 12 & $30.2(1159)$ & - \\
\hline 13 & $24.9(956)$ & - \\
\hline$\geq 14^{\mathrm{b}}$ & $17.3(662)$ & - \\
\hline Missing, (n) & $(0)$ & - \\
\hline$\leq 15^{\mathrm{c}}$ & - & $35.1(676)$ \\
\hline 16 & - & $29.8(575)$ \\
\hline$\geq 17^{d}$ & - & $35.1(675)$ \\
\hline Missing, (n) & - & (10) \\
\hline \multicolumn{3}{|l|}{ Maternal education } \\
\hline Middle school or less & $14.5(553)$ & $16.2(312)$ \\
\hline High school & $18.5(703)$ & $26.7(514)$ \\
\hline Diploma $^{\mathrm{e}}$ & $24.3(924)$ & $17.6(340)$ \\
\hline Bachelor's degree or higher & $42.7(1626)$ & 39.5 (762) \\
\hline Missing, (n) & $(30)$ & (8) \\
\hline \multicolumn{3}{|l|}{ Paternal education } \\
\hline Middle school or less & $18.1(684)$ & $16.5(316)$ \\
\hline High school & $23.1(876)$ & $27.8(535)$ \\
\hline Diploma $^{e}$ & $23.1(873)$ & $16.5(317)$ \\
\hline Bachelor's degree or higher & $35.7(1353)$ & $39.2(753)$ \\
\hline Missing, (n) & $(50)$ & (15) \\
\hline \multicolumn{3}{|c|}{ Monthly household income (KWD) } \\
\hline$<1000$ & $14.2(487)$ & 16.4 (173) \\
\hline $1000-1500$ & 28.5 (978) & $26.0(275)$ \\
\hline $1501-2000$ & $16.9(579)$ & $17.4(184)$ \\
\hline $2001-2500$ & $15.1(516)$ & $11.8(125)$ \\
\hline $2501-3000$ & $12.5(428)$ & $14.6(154)$ \\
\hline$>3000$ & $12.8(438)$ & $13.8(146)$ \\
\hline Missing, (n) & (410) & (879) \\
\hline
\end{tabular}

KWD: 1 Kuwaiti Dinar about 3.21 US\$. a The youngest age reported was 9 years. b The oldest age reported was 17 years. c The youngest age reported was 12 years. $d$ The oldest age reported was 20 years. e Refers to a two-year associate degree post high school. 
reported having a bachelor's degree or higher. The most commonly reported $(28.5 \%, 978 / 3426)$ total monthly household income was between 1000 and $1500 \mathrm{KWD}$ among middle school participants. On the other hand, 1959 high school students were enrolled, of which 1936 (1049 girls and 887 boys) were analyzed in this report (i.e. excluding 23 participants with missing information on household SHS exposure). The majority of the enrolled high school students were aged between 14 years (5th percentile) and 18 years (95th percentile), with a median age of 16 years. Majority of mothers $(39.5 \%$, $762 / 1928)$ and fathers $(39.2 \%, 753 / 1921)$ of the enrolled high school students reported having an education level of bachelor's degree or higher. Among high school participants, the most commonly reported (26.0\%, 275/1057) total monthly household income was between 1000 and $1500 \mathrm{KWD}$.

Overall, 45.8\% (1755/3836; 95\% CI: 44.2-47.3) of the enrolled middle school students and $51.6 \%$ (998/1936; 95\% CI: 49.3-53.8) of the enrolled high school students were exposed to household SHS (Table 2). Among the enrolled middle and high school students, exposure to household SHS was similar across gender. Exposure to household SHS increased as age increased. For example, among the sample of high school students, $48.1 \%$ of those aged $\leq 15$ years were exposed compared to $56.3 \%$ of those aged $\geq 17$ years. Among the sample of middle and high school students, household SHS exposure

Table 2. Prevalence estimates of household secondhand smoke (SHS) exposure in the total population and according to personal and familial characteristics: results from the two analyzed studies

\begin{tabular}{|c|c|c|c|c|}
\hline \multirow[t]{2}{*}{ Characteristics } & \multicolumn{2}{|c|}{ Viddle School students } & \multicolumn{2}{|c|}{ Iligh School students } \\
\hline & $\begin{array}{c}\text { SHIS exposure } \\
\%_{0} \text { (n total) }\end{array}$ & $\mathrm{APR} *(95 \% \mathrm{CI})$ & $\begin{array}{c}\text { SIS exposure } \\
\% \text { (n total) }\end{array}$ & $\mathrm{APR}^{\circ}\left(95^{\circ} \circ \mathrm{CI}\right)$ \\
\hline Total & $45.8(1755 / 3836)$ & - & $51.6(998 / 1936)$ & - \\
\hline \multicolumn{5}{|l|}{ Adolescent gender } \\
\hline Female & $46.3(998 / 2154)$ & 1.00 (Ref.) & $52.5(551 / 1049)$ & 1.00 (Ref.) \\
\hline Male & $45.0(757 / 1682)$ & $0.99(0.92-1.07)$ & $50.4(447 / 887)$ & $0.96(0.88-1.04)$ \\
\hline p-value & 0.413 & & 0.349 & \\
\hline \multicolumn{5}{|l|}{ Adolescent age group (years) } \\
\hline$\leq 11^{\text {a }}$ & $42.5(450 / 1059)$ & 1.00 (Ref.) & - & - \\
\hline 12 & $47.5(550 / 1159)$ & $1.09(0.99-1.20)$ & - & - \\
\hline 13 & $46.6(445 / 956)$ & $1.07(0.97-1.18)$ & - & - \\
\hline$\geq 14^{b}$ & $46.8(310 / 662)$ & $1.05(0.95-1.18)$ & - & - \\
\hline$\leq 15^{c}$ & - & - & $48.1(325 / 676)$ & 1.00 (Ref.) \\
\hline 16 & - & - & $50.3(289 / 575)$ & $1.02(0.91-1.13)$ \\
\hline$\geq 17$ years $^{\mathrm{d}}$ & - & - & $56.3(380 / 675)$ & $1.11(1.01-1.23)$ \\
\hline p-value & 0.092 & & 0.008 & \\
\hline \multicolumn{5}{|l|}{ Maternal education } \\
\hline Middle school or less & $50.6(280 / 553)$ & $1.07(0.97-1.17)$ & $55.8(174 / 312)$ & $1.08(0.95-1.24)$ \\
\hline High school & $52.8(371 / 703)$ & $1.13(1.02-1.25)$ & $56.0(288 / 514)$ & $1.11(0.99-1.24)$ \\
\hline Diploma $^{e}$ & $46.7(431 / 924)$ & $1.03(0.92-1.16)$ & $54.1(184 / 340)$ & $1.14(1.01-1.29)$ \\
\hline Bachelor's degree or higher & $40.5(659 / 1626)$ & 1.00 (Ref.) & $45.4(346 / 762)$ & 1.00 (Ref.) \\
\hline p-value & $<0.001$ & & $<0.001$ & \\
\hline \multicolumn{5}{|l|}{ Paternal education } \\
\hline Middle school or less & $59.1(404 / 684)$ & $1.60(1.44-1.79)$ & $59.8(189 / 316)$ & $1.28(1.13-1.46)$ \\
\hline High school & $53.0(464 / 876)$ & $1.45(1.30-1.61)$ & $57.6(308 / 535)$ & $1.25(1.12-1.40)$ \\
\hline Diploma $^{e}$ & $47.0(410 / 873)$ & $1.31(1.17-1.46)$ & $51.4(163 / 317)$ & $1.14(1.00-1.31)$ \\
\hline Bachelor's degree or higher & $33.5(453 / 1353)$ & 1.00 (Ref.) & $44.0(331 / 753)$ & 1.00 (Ref.) \\
\hline p-value & $<0.001$ & & $<0.001$ & \\
\hline
\end{tabular}


Table 2. Continued

\begin{tabular}{|c|c|c|c|c|}
\hline \multirow[t]{2}{*}{ Characteristics } & \multicolumn{2}{|c|}{ Viddlle School students } & \multicolumn{2}{|c|}{ Iligh School students } \\
\hline & $\begin{array}{l}\text { SIIS exposure } \\
\% \text { (n lotal) }\end{array}$ & $A P R^{*}\left(95^{\circ} \% \mathrm{CI}\right)$ & $\begin{array}{c}\text { SIIS exposure } \\
\% \text { (n total) }\end{array}$ & $\mathrm{APR}^{*}\left(95^{\circ} \% \mathrm{CI}\right)$ \\
\hline \multicolumn{5}{|c|}{ Monthly household income (KWD) } \\
\hline$<1000$ & $50.5(246 / 487)$ & $1.16(0.98-1.37)$ & $57.8(100 / 173)$ & $1.53(1.20-1.95)$ \\
\hline $1000-1500$ & $51.1(500 / 978)$ & $1.15(0.99-1.34)$ & $53.2(146 / 275)$ & $1.29(1.02-1.62)$ \\
\hline $1501-2000$ & $48.7(282 / 579)$ & $1.14(0.98-1.34)$ & $52.2(96 / 184)$ & $1.23(0.96-1.56)$ \\
\hline $2001-2500$ & $44.4(229 / 516)$ & $1.12(0.96-1.31)$ & $52.8(66 / 125)$ & $1.28(0.99-1.65)$ \\
\hline $2501-3000$ & $38.6(165 / 428)$ & $1.01(0.85-1.20)$ & $53.9(83 / 154)$ & $1.33(1.05-1.69)$ \\
\hline$>3000$ & $35.8(157 / 438)$ & 1.00 (Ref.) & $40.4(59 / 146)$ & 1.00 (Ref.) \\
\hline$p$-value & $<0.001$ & & 0.013 & \\
\hline
\end{tabular}

KWD: 1 Kuwaiti Dinar about 3.21 US\$. SHS: secondhand smoke. Cl: confidence interval. *APR: adjusted prevalence ratio, simultaneously adjusted for all variables shown in the Table. a The youngest age reported was 9 years. b The oldest age reported was 17 years. c The youngest age reported was 12 years. $d$ The oldest age reported was 20 years. e Refers to a two-year associate degree post high school.

prevalence showed significant increasing trends as maternal/paternal education level and monthly household income decreased. For instance, among middle school students who participated in the study, paternal educational attainment of middle school or less compared to bachelor's degree or higher was associated with 1.60 times (95\% CI: 1.44-1.79) higher household SHS exposure. In regard to monthly household income, among the study sample, $50.5 \%$ of middle school students from families reporting income of less than $1000 \mathrm{KWD}$ a month were exposed to household SHS compared to $35.8 \%$ of middle school students who reported the highest monthly family income of more than $3000 \mathrm{KWD}$.

Additional analysis on the role of self-smoking on SHS exposure prevalence was conducted among the sample of high school students. The prevalence of current cigarette self-smoking among the enrolled high school students was estimated to be $13.7 \%$ (264/1925; data not shown). Among those who are not current cigarette smokers, the prevalence of household SHS exposure was 49.4\% (821/1661), whereas among those who are current cigarette smokers, the prevalence of SHS exposure was $65.5 \%$ $(173 / 264)$.

\section{DISCUSSION}

This study sought to estimate the prevalence of household SHS exposure among adolescents (samples of middle and high school students) in Kuwait and explore disparities in household SHS exposure according to parental education and socioeconomic status. The findings of this study demonstrated that nearly half of adolescents enrolled in the analyzed cross-sectional studies in Kuwait are exposed to household SHS (45.8\% of middle school students and $51.6 \%$ of high school students). Estimates of SHS exposure in this report are higher than the estimate from the Global Youth Tobacco Survey that found $30.4 \%$ of 356414 never-smoking adolescents in 168 countries to be exposed to household SHS ${ }^{22}$. Similarly, our estimates of SHS exposure exceeded a prior global estimate of $40 \%$ among children ${ }^{5}$. However, our estimates are slightly lower than another global estimate among adolescents living in low- and middle-income countries of $55.9 \%{ }^{6}$. At the regional level, household SHS exposure among a sample of middle and high school students in Saudi Arabia was similar to our findings at $49.3 \%{ }^{23}$. Moreover, our results demonstrated that enrolled adolescents of mothers and fathers with low educational attainment and those from families with low income were the most vulnerable to household SHS exposure. Such observations are consistent with previous investigations that showed low socioeconomic status and low parental education are associated with higher SHS exposure among children ${ }^{24,25}$.

Further analysis among the enrolled high school students showed that SHS exposure was higher among adolescents who reported current cigarette smoking compared to those who do not currently smoke cigarettes (65.5\% vs $49.4 \%)$. Such an observation is in agreement with existing literature ${ }^{26}$. Moreover, this observation indicates that a significant 
proportion (49.4\%) of non-smoking high school students in Kuwait are being exposed to household SHS. Such a result is comparable to results from 25 African countries that showed around $45 \%$ of neversmoking adolescents in Africa are exposed to $\mathrm{SHS}^{27}$. However, our estimate of $49.4 \%$ SHS exposure among non-smoking adolescents is higher than an estimate of $32.0 \%$ among non-smoking US adolescents aged $12-$ 19 years, in $2014^{13}$. Overall, these results are alarming and indicate that non-smoking adolescents in Kuwait are being exposed to high rates of household SHS.

The detrimental effects of SHS exposure on health and its predisposing effects on never-smoking adolescents to initiate smoking are demonstrated in the literature ${ }^{28,29}$. Moreover, emerging evidence suggesting that SHS exposure is a risk factor for delayed neurodevelopment and cognitive impairment in children further highlights the adverse effects of SHS exposure among children ${ }^{30}$. This report has documented that a substantial proportion of adolescents in Kuwait who participated in the analyzed studies are exposed to household SHS. Therefore, local public health policies should be developed to address this issue. Efforts should be made to increase parental awareness of the detrimental impact of SHS exposure on their children and be encouraged to ensure smoke-free homes and cars. Although laws banning smoking in public places have been enforced at the national level, there is clearly a need for policies and strategies to tackle smoking at the household level. To ultimately reduce SHS exposure, reducing smoking in the community should be addressed first.

\section{Strengths and limitations}

A major strength of the current work is the representative and large samples of middle and high school students, which increases the external validity of our findings. A potential limitation is the possibility of underreporting of household SHS exposure by parents, which has been demonstrated by previous studies ${ }^{18,31}$. Another limitation to our study is the lack of confirmatory information on the extent of 'inside' the house exposure. For instance, smokers might choose to smoke in a separate room in the house or during the time when the children are not in the house. Hence, such practices might affect the true prevalence of SHS exposure.

Moreover, future studies should objectively assess household smoking-related air pollution and children's urine cotinine to supplement and validate the self-reported SHS exposure. Current self-smoking status was assessed in the sample of high school students and showed that SHS exposure differs according to self-smoking status. The lack of information on self-smoking status in the sample of middle school students is a further limitation to our analysis. Moreover, not having information on the specific type of smoke (i.e. smoke from cigarettes, waterpipe etc.) that children are exposed to is a further limitation.

\section{CONCLUSIONS}

A large proportion of participating adolescents in Kuwait are exposed to household SHS, which highlights the need for developing and implementing a comprehensive strategy to control tobacco consumption at the national level. Such a strategy will eventually reduce SHS exposure in the vulnerable youth population, particularly in disadvantaged families.

\section{REFERENCES}

1. U.S. Department of Health and Human Services. The Health Consequences of Involuntary Exposure to Tobacco Smoke: A Report of the Surgeon General. Atlanta, GA: U.S. Department of Health and Human Services, Centers for Disease Control and Prevention, Coordinating Center for Health Promotion, National Center for Chronic Disease Prevention and Health Promotion, Office on Smoking and Health; 2006.

2. Diver WR, Jacobs EJ, Gapstur SM. Second-hand Smoke Exposure in Childhood and Adulthood in Relation to Adult Mortality Among Never Smokers. Am J Prev Med. 2018;55(3):345-352. doi:10.1016/j.amepre.2018.05.005

3. Raghuveer G, White DA, Hayman LL, et al. Cardiovascular Consequences of Childhood Secondhand Tobacco Smoke Exposure: Prevailing Evidence, Burden, and Racial and Socioeconomic Disparities: A Scientific Statement From the American Heart Association. Circulation. 2016;134(16):e336-e359. doi:10.1161/CIR.0000000000000443

4. Barnoya J, Glantz SA. Cardiovascular effects of second-hand smoke: nearly as large as smoking. Circulation. 2005;111(20):2684-2698. doi:10.1161/CIRCULATIONAHA.104.492215

5. Oberg M, Jaakkola MS, Woodward A, Peruga A, PrussUstun A. Worldwide burden of disease from exposure to second-hand smoke: a retrospective analysis of data from 192 countries. Lancet. 2011;377(9760):139-146. doi:10.1016/S0140-6736(10)61388-8 
6. Xi B, Liang Y, Liu Y, et al. Tobacco use and secondhand smoke exposure in young adolescents aged 1215 years: data from 68 low-income and middle-income countries. Lancet Glob Health. 2016;4(11):e795-e805. doi:10.1016/S2214-109X(16)30187-5

7. Kuntz B, Lampert T. Social disparities in parental smoking and young children's exposure to second-hand smoke at home: a time-trend analysis of repeated crosssectional data from the German KiGGS study between 2003-2006 and 2009-2012. BMC Public Health. 2016;16. doi:10.1186/s12889-016-3175-x

8. Gartner CE, Hall WD. Is the socioeconomic gap in childhood exposure to second-hand smoke widening or narrowing? Tob Control. 2013;22(5):344-348. doi:10.1136/tobaccocontrol-2011-050297

9. Pisinger C, Hammer-Helmich L, Andreasen AH, Jorgensen T, Glumer C. Social disparities in children's exposure to second hand smoke at home: a repeated cross-sectional survey. Environ Health. 2012;11. doi:10.1186/1476-069X-11-65

10. Moore GF, Currie D, Gilmore G, Holliday JC, Moore L. Socioeconomic inequalities in childhood exposure to second-hand smoke before and after smoke-free legislation in three UK countries. J Public Health. 2012;34(4):599-608. doi:10.1093/pubmed/fds025

11. Moore GF, Moore L, Littlecott HJ, et al. Prevalence of smoking restrictions and child exposure to second-hand smoke in cars and homes: a repeated cross-sectional survey of children aged 10-11 years in Wales. BMJ Open. 2015;5(1):e006914. doi:10.1136/bmjopen-2014-006914

12. Jarvis MJ, Feyerabend C. Recent trends in children's exposure to second-hand smoke in England: cotinine evidence from the Health Survey for England. Addiction. 2015;110(9):1484-1492. doi:10.1111/add.12962

13. Tsai J, Homa DM, Gentzke AS, et al. Exposure to Secondhand Smoke Among Nonsmokers - United States, 1988-2014. MMWR Morb Mortal Wkly Rep. 2018;67(48):1342-1346. doi:10.15585/mmwr.mm6748a3

14. Protano C, Cammalleri V, Antonucci A, et al. Further Insights on Predictors of Environmental Tobacco Smoke Exposure during the Pediatric Age. Int J Environ Res Public Health. 2019;16(21). doi:10.3390/ijerph16214062

15. Protano C, Valeriani F, Macedonio A, et al. Family-based social determinants and child health: Cross-sectional study. Pediatr Int. 2017;59(2):201-208. doi: 10.1111/ped.13097

16. Lopez MJ, Arechavala T, Continente X, Schiaffino A, Perez-Rios M, Fernandez E. Social inequalities in secondhand smoke exposure in children in Spain. Tob Induc Dis. 2018;16(April). doi:10.18332/tid/85717

17. Chen X, Stanton B, Hopper J, Khankari N. Sources, locations, and predictors of environmental tobacco smoke exposure among young children from inner-city families. J Pediatr Health Care. 2011;25(6):365-372. doi:10.1016/j.pedhc.2010.04.014

18. Berman T, Barnett-Itzhaki Z, Axelrod R, et al. Socioeconomic inequalities in exposure to environmental tobacco smoke in children in Israel. Environ Int. 2018;121(Pt 1):643-648. doi:10.1016/j.envint.2018.09.034

19. Ziyab AH. Prevalence of food allergy among schoolchildren in Kuwait and its association with the coexistence and severity of asthma, rhinitis, and eczema: A cross-sectional study. World Allergy Organ J. 2019;12(4):100024. doi:10.1016/j.waojou.2019.100024

20. Almari M, Alsaedi S, Mohammad A, Ziyab AH. Associations of adiposity and parental diabetes with prediabetes among adolescents in Kuwait: A crosssectional study. Pediatr Diabetes. 2018;19(8):1362-1369. doi:10.1111/pedi.12780

21. Zou G. A modified poisson regression approach to prospective studies with binary data. Am J Epidemiol. 2004;159(7):702-706. doi:10.1093/aje/kwh090

22. Veeranki SP, Mamudu HM, Zheng S, et al. Secondhand smoke exposure among never-smoking youth in 168 countries. J Adolesc Health. 2015;56(2):167-173. doi:10.1016/j.jadohealth.2014.09.014

23. Al-Zalabani AH, Amer SM, Kasim KA, Alqabshawi RI, Abdallah AR. Second-Hand Smoking among Intermediate and Secondary School Students in Madinah, Saudi Arabia. Biomed Res Int. 2015;2015. doi:10.1155/2015/672393

24. Orton S, Jones LL, Cooper S, Lewis S, Coleman T. Predictors of children's second-hand smoke exposure at home: a systematic review and narrative synthesis of the evidence. PLoS One. 2014;9(11):e112690. doi:10.1371/journal.pone.0112690

25. Jurado D, Munoz C, Luna Jde D, Fernandez-Crehuet M. Environmental tobacco smoke exposure in children: parental perception of smokiness at home and other factors associated with urinary cotinine in preschool children. J Expo Anal Environ Epidemiol. 2004;14(4):330-336. doi:10.1038/sj.jea.7500329

26. Jain RB. Rates of exposure to environmental tobacco smoke from various indoor environments among US children and nonsmoker adolescents and adults. Environ Sci Pollut Res Int. 2018;25(17):17002-17011. doi:10.1007/s11356-018-1891-8

27. Owusu D, Mamudu HM, John RM, Ibrahim A, Ouma AE, Veeranki SP. Never-Smoking Adolescents' Exposure to Secondhand Smoke in Africa. Am J Prev Med. 2016;51(6):983-998. doi:10.1016/j.amepre.2016.08.040

28. Lee KA, Palipudi KM, English LM, Ramanandraibe N, Asma S, GYTS collaborative group. Second-hand smoke exposure and susceptibility to initiating cigarette smoking among never-smoking students in selected African countries: Findings from the Global Youth Tobacco Survey. Prev Med. 2016;91S:S2-S8. doi:10.1016/j.ypmed.2016.04.017

29. Warren CW, Jones NR, Eriksen MP, Asma S. Patterns of global tobacco use in young people and implications for future chronic disease burden in adults. Lancet. 2006;367(9512):749-753. doi:10.1016/S0140-6736(06)68192-0

30. Chen R, Clifford A, Lang L, Anstey KJ. Is exposure to second-hand smoke associated with cognitive 
parameters of children and adolescents?--a systematic literature review. Ann Epidemiol. 2013;23(10):652-661. doi:10.1016/j.annepidem.2013.07.001

31. Boyaci H, Etiler N, Duman C, Basyigit I, Pala A. Environmental tobacco smoke exposure in school children: parent report and urine cotinine measures. Pediatr Int. 2006;48(4):382389. doi:10.1111/j.1442-200X.2006.02225.x

\section{ACKNOWLEDGEMENTS}

We are grateful to the children and their parents who participated in the two studies. Additionally, we sincerely appreciate the cooperation, coordination, and assistance of the staff at the different schools. For the study conducted among middle school students, we thank Mahdi Hussain, Mohammad Ghadhanfar and Anwar Al-Baloul for their considerable assistance with data collection and data entry. For the study conducted among high school students, we thank the nursing team and field workers, namely Khalid H. Alenezi, Waleed F. Alrasheedi, Nawaf M. Alqattan, Jerome Tacaisan, Samer H. Noufal, Tamer M. Attiy, Mohamed F. Khalaf, Hazzel J. Lera, Liby K. Thomas, and Junna M. Casimina.

\section{CONFLICTS OF INTEREST}

The authors have completed and submitted the ICMJE Form for Disclosure of Potential Conflicts of Interest and none was reported.

\section{FUNDING}

The study conducted among middle school students was funded partially by the Kuwait Foundation for the Advancement of Sciences under project code: P115-13MC-05. Additionally, this study was supported and funded by Kuwait University, Research Project No. MC01/16. The study conducted among high school students was partially funded by the Kuwait National Guard, College of Graduate Studies at Kuwait University, and the Salman Abdullah Al Dabbous \& Sons Company. The funders had no role in study design, collection, analysis and interpretation of the data, decision to publish, or preparation of the manuscript.

\section{AUTHORS' CONTRIBUTIONS}

AHZ conceived, designed and planned the study among middle school students, obtained funding, supervised the research conducted, analyzed and interpreted the data, and drafted the manuscript. MA conceived, designed and planned the study among high school students, obtained funding, supervised the research conducted, and contributed to data interpretation. AAT contributed to the epidemiological design of study and contributed to data interpretation. All authors critically revised the manuscript for important intellectual content. The manuscript was read and approved by all authors.

Not commissioned; externally peer reviewed. 